\title{
Effect of dip wash treatments with organic acids and acidic electrolyzed water combined with ultraviolet irradiation on quality of strawberry fruit during storage
}

\author{
Violeta Nour $r^{1,2, *}$ (D), Alina Madalina Plesoianu² (D), Mira Elena Ionica ${ }^{1}$ (D) \\ 1. University of Craiova - Faculty of Horticulture - Department of Horticulture \& Food Science - Craiova, Romania. \\ 2. Dunarea de Jos University of Galati - Faculty of Food Science and Engineering - Department of Food Science and Engineering - Galati, \\ Romania. \\ Received: Oct. 18, 2020 | Accepted: Feb. 9, 2021 \\ Section Editor: Juliana Sanches \\ *Corresponding author: vionor@yahoo.com \\ How to cite: Nour, V., Plesoianu, A. M., Ionica, M. E. (2021). Effect of dip wash treatments with organic acids and acidic electrolyzed water combined \\ with ultraviolet irradiation on quality of strawberry fruit during storage. Bragantia, 80, e1921. https://doi org/10.1590/1678-4499.20200440
}

\begin{abstract}
The objective of this study was to determine the effects of dip wash treatments with $2 \%$ citric acid (CA), $0.2 \%$ benzoic acid (BA), $0.2 \%$ sorbic acid (SA) and acidic electrolyzed water (AEW) followed by $2 \mathrm{~kJ} \cdot \mathrm{m}^{-2}$ ultraviolet (UV) irradiation on the postharvest decay and quality of strawberry fruit cultivar 'Malvina', as compared to control, and UV alone treated samples. Weight loss, firmness, soluble solids content, titratable acidity, total phenolics content, total anthocyanins content, antioxidant activity and decay incidence of control and treated strawberry fruits were investigated during cold storage at $8^{\circ} \mathrm{C}$ for 21 days. The result showed that UV-treated fruits had a lower weight loss, higher titratable acidity, phenolic and anthocyanin content and were firmer than the untreated fruits. Dip wash in AEW before UVC treatment reduced weight loss and increased firmness of strawberry fruits but did not significantly affect total phenolic content, total anthocyanins content, 2,2-diphenyl-1-picrylhydrazyl (DPPH) antioxidant activity and fruit decay. Dip wash treatment with organic acids followed by UVC irradiation was significantly more effective than UV treatment alone in reducing fruit decay and weight loss and in maintaining at higher levels titratable acidity, total anthocyanins content, total phenolic content and antioxidant activity of strawberries during refrigerated storage. The present findings demonstrate that dip wash treatment with $0.2 \%$ SA, $0.2 \%$ BA or $2 \%$ CA followed by UV treatment can be an effective method for maintaining the phytochemical content and delaying the decay of strawberry fruit during cold storage.
\end{abstract}

Key words: Fragaria $\times$ ananassa, benzoic acid, citric acid, sorbic acid, antioxidant activity, postharvest decay.

\section{INTRODUCTION}

Strawberry (Fragaria $\times$ ananassa Duch.) is a very popular fruit with huge nutraceutical and commercial value, appreciated by consumers for its unique flavor and nutritious qualities (Bianco et al. 2009; Parvez and Wani 2018). Strawberries contain high levels of phytochemicals, such as anthocyanins, flavonoids and phenolic acids, that strongly influence the sensorial and nutritional quality of the fruits and possess excellent free radical scavenging capacity (Erkan et al. 2008). They are characterized by high respiration and metabolic rates determining a rapid tissue softening and degradation during the last stages of development (Pombo et al. 2009; Aday et al. 2013; Moya-León et al. 2019). The loss of fruit firmness during ripening and the sensitivity to fungal attack is mainly due to the continuous decrease of cell wall content as a result of the solubilization and depolymerization of cell wall components, (i.e., polyuronides and hemicelluloses) and to the loss of neutral sugars (Pombo et al. 2009; Bal 2019).

Fresh strawberries have a short shelf life (5 to 7 days) when stored under normal atmospheric conditions at $0{ }^{\circ} \mathrm{C}$, fruit losses can be up to 40\% during storage (Collins and Perkins-Veazie 1993; Guo et al. 2018). As a consequence, 
there is a current interest in the enhancement of strawberry fruit shelf life by using various techniques, like controlled atmosphere storage, modified atmosphere packaging, high oxygen treatment, ultraviolet (UVC) or gamma irradiation, edible coatings, chemical treatments, etc. (Parvez and Wani 2018). Washing treatments in sanitizer solutions are useful and effective methods to inactivate pathogenic and spoilage microorganisms on fresh fruits. Among sanitizers, chlorine and its derivatives were the most widely used due to their low relative cost, ease of use and effectiveness. In the past years, other sanitizers like organic acids and acidic electrolyzed water (AEW) have been evaluated in the fruit processing industry as effective disinfection alternatives to chlorine in order to avoid the risks associated with exposure to chlorinated organic by-products and to meet current safety standards (Ma et al. 2017; Pablos et al. 2018; Nicolau-Lapeña et al. 2019). In addition, the nonthermal physical treatments, such as ultrasound or ultraviolet processing, have shown effectiveness and significant advantages in ensuring microbial safety of fresh fruits (Deng et al. 2020). Organic acids, such as citric (CA), benzoic (BA) and sorbic (SA) acids, have been used to control spoilage or pathogenic bacteria on fresh and freshcut fruits and vegetables by disturbing their ionic permeability across the membrane, anion accumulation and decreasing the internal cellular $\mathrm{pH}$ (Parish et al. 2003). Likewise, several previous studies have reported on the effectiveness of AEW to inactivate contaminant microbiota on fresh-cut apples, carrots and on ready-to-eat vegetables and sprouts (Graça et al. 2011; Issa-Zacharia et al. 2011; Koide et al. 2011).

Exposure to low UVC radiation doses $\left(0.43,2.15\right.$ and $\left.4.30 \mathrm{~kJ} \cdot \mathrm{m}^{-2}\right)$ has been reported to reduce postharvest decay of fresh fruits and vegetables by increasing the resistance of tissues to storage pathogens. These have been related to the increase in the transcription and activity of a set of enzymes and proteins involved in the defense against pathogens and to the biosynthesis of several secondary metabolites with antioxidant, antifungal and/or antibacterial activity (Erkan et al. 2008; Severo et al. 2015). Delaying of the ripening process and reduction of fruit softening by UVC application have also been reported (Baka et al. 1999, Pan et al. 2004; Pombo et al. 2009). Furthermore, some previous studies have shown that the combination of UVC with other preservative methods (edible coatings, heat treatment) have achieved good results in extending the postharvest life of fruits and vegetables and in maintaining their quality (Bal 2019; Pan et al. 2004; Lin et al. 2017).

The present study was conducted to investigate the effects of postharvest chemical treatments followed by UVC irradiation on fruit quality attributes (weight loss, firmness, titratable acidity, total soluble solids), bioactive compounds (total phenolics, total anthocyanins) and antioxidant activity of 'Malvina' strawberries during 21 days storage at $8{ }^{\circ} \mathrm{C}$. The effectiveness of these treatments in reducing decay of strawberry fruits was also examined.

\section{MATERIAL AND METHODS}

\section{Plant material and treatment}

Strawberry fruits (Fragaria $\times$ ananassa) of the cultivar 'Malvina' were hand-harvested in 2020 at the commercially mature stage from an orchard near Marsani $\left(44^{\circ} 00^{\prime} 56^{\prime \prime} \mathrm{N}, 23^{\circ} 59^{\prime} 30^{\prime \prime} \mathrm{E}\right)$, a village located in Oltenia, region of Romania. Strawberry was cultivated by applying conventional farming practice for growing in open air. The fruits were sorted to eliminate damage, poor quality and unripe fruit and selected for uniform size, color and maturity. After removing the calyx and peduncle, fruits were washed in tap water, then drained at ambient temperature, placed on filter paper and randomly divided into six groups (80 fruits per group) corresponding to the following treatments: $(\mathrm{C})$ - fruits dipped in tap water; (UV) - fruits dipped in tap water and UVC irradiated; (CA + UV) - fruits dipped in $2 \%$ citric acid and UVC irradiated; (AEW + UV) - fruits dipped in acidic electrolyzed water and UVC irradiated; (BA + UV) - fruits dipped in $0.2 \%$ benzoic acid and UVC irradiated; (SA + UV) - fruits dipped in $0.2 \%$ sorbic acid and UVC irradiated. Dipping time in the treatment solutions was about $5 \mathrm{~min}$ at ambient temperature $\left(20^{\circ} \mathrm{C}\right)$.

Ultraviolet radiation was performed under ambient conditions using a light LED UVC bulb germicidal lamp with peak emission at $254 \mathrm{~nm}\left(60 \mathrm{~W}, \mathrm{AC} 100-277 \mathrm{~V}\right.$, China). An UVC irradiation dose of $2.0 \mathrm{~kJ} \cdot \mathrm{m}^{-2}$ was used in this study based on the 
results reported by Wang et al. (2015) and Jin et al. (2017) who found that this was the most effective dose for inhibiting decay and maintaining quality in strawberry fruits.

The UVC set up was placed in a fume hood and fruits were allowed to dry before UV treatment. Fruits were placed in a single layer for the UV treatment and were irradiated during $30 \mathrm{~min}$ at approximately $30 \mathrm{~cm}$ under the lamp, to obtain a dose of $2.0 \mathrm{~kJ} \cdot \mathrm{m}^{-2}$. The UVC irradiation intensity was measured using a UVC portable digital radiometer (TN-2254, Taine Co., Ltd., Taiwan, China).

Immediately after the treatment, fruits were randomly placed in disposable plastic containers ( $500 \mathrm{~mL}$ capacity), each containing 16 to 20 fruits (about $240 \mathrm{~g}$ ), covered by a lid and stored at $8{ }^{\circ} \mathrm{C}$ for 21 days. Untreated (control) fruits were stored under the same conditions. Each treatment was replicated three times and the experiment was repeated twice. Four containers were used for each replicate. Weight loss, firmness, total soluble solids, titratable acidity, total phenolic content, total anthocyanins content, antioxidant activity and fruit decay were evaluated at 0, 7, 14 and 21 days of storage. Each determination was run in triplicate.

\section{Chemicals}

Folin-Ciocalteu reagent, gallic acid, 2,2-diphenyl-1-picrylhydrazyl (DPPH), 6-hydroxy-2,5,7,8-tetramethylchroman2-carboxylic acid (Trolox) and sodium acetate were purchased from Sigma-Aldrich (Germany). Benzoic acid, sorbic acid and sodium carbonate were purchased from Merck (Darmstadt, Germany). All other chemicals used were of analytical grade. The acidic electrolyzed water used in this study is acidic water produced from Kangen Water Type LeveLuk SD 501 apparatus (Enagic, Dusseldorf, Germany).

\section{Weight loss}

Fruit weights were determined using a sensitive digital scale (Sartorius CP124S, UK, accuracy $=0.01 \mathrm{~g}$ ). Weight loss during storage was determined by measuring the fruit weight at the beginning of the experiment and at the end of each storage period and was expressed as the percentage of weight loss with respect to the initial weight.

\section{Firmness}

The fruit firmness was measured using a GY-3 fruit penetrometer (Sundoo Instruments, Zhejiang, China) fitted with a round plunger ( $6 \mathrm{~mm}$ diameter). An even force was applied to the penetrometer tip to penetrate the fruit tissue. Eight fruits from each replicate were analyzed in opposite sides of the equatorial zone for each treatment and storage time assayed and the average value was reported in $\mathrm{kg} \cdot \mathrm{cm}^{-2}$.

\section{Fruit decay}

The external appearance of strawberries was evaluated after 7, 14 and 21 days of storage. Strawberry fruits showing macroscopic fungal growth or injuries on the fruit surface were considered decayed. Fruit decay was expressed as percent of fruit showing decay symptoms.

\section{Titratable acidity}

The titratable acidity was titrimetrically determined in $10 \mathrm{~g}$ of homogenate from three fruits, made up to $100 \mathrm{~g}$ with deionized water and titrated to $\mathrm{pH} 8.2$ with $0.1 \mathrm{M} \mathrm{NaOH}$ solution. The results were expressed as grams of citric acid per $100 \mathrm{~g}$ fresh weight. Two independent extracts were prepared and each one was titrated in duplicate. 


\section{Total soluble solids}

Homogenous sample was prepared by blending twenty fruits from replicate sample in an electrical blender. The total soluble solids content was determined by using a digital refractometer (Hanna Instruments, Woonsocket, USA) and the results were expressed as percentage of soluble solids.

\section{Extraction}

Strawberry homogenates $(3 \mathrm{~g})$ were extracted with methanol $(100 \mathrm{~mL})$ in an ultrasonic bath for $60 \mathrm{~min}$ at room temperature $\left(20^{\circ} \mathrm{C}\right)$. The extracts were then centrifuged at $6000 \mathrm{rpm}$ for $15 \mathrm{~min}$. The supernatants were transferred to vials, stored at $-40^{\circ} \mathrm{C}$, and later used for total phenolic content and DPPH free radical-scavenging activity.

\section{Total phenolic content}

The total phenolic content was assessed according to the Folin-Ciocalteu procedure (Singleton and Rossi 1965). Briefly, a $100 \mu \mathrm{L}$ aliquot of extract was mixed with $5 \mathrm{~mL}$ of distilled water and $500 \mu \mathrm{L}$ of Folin-Ciocalteu reagent. After 3 min, $1.5 \mathrm{~mL}$ of $(20 \% \mathrm{w} / \mathrm{v})$ sodium carbonate solution was added and the reaction mixture was diluted with distilled water to a final volume of $10 \mathrm{~mL}$. After shaking vigorously and incubating in the dark at $40{ }^{\circ} \mathrm{C}$ for $30 \mathrm{~min}$, the absorbance was measured at $765 \mathrm{~nm}$ on a Varian Cary 50 UV spectrophotometer (Varian Co., USA). A calibration curve was prepared using standard solutions of gallic acid. Results were expressed as milligrams of gallic acid equivalents (GAE) per 100 fresh weight (fw).

\section{Antioxidant activity}

The free radical scavenging activity of the extracts against DPPH free radical was evaluated based on the method described by Oliveira et al. (2008). An aliquot (50 $\mu \mathrm{L})$ of fruit extract was mixed with $3 \mathrm{~mL}$ of DPPH methanolic solution $(0.004 \%)$. The mixture was shaken vigorously and kept in the dark for $30 \mathrm{~min}$. After incubation, the absorbance was measured at $517 \mathrm{~nm}$ on a Varian Cary 50 UV-VIS spectrophotometer against a blank of methanol without DPPH. The inhibition of the DPPH radical by the samples was calculated according to the following formula:

$$
\text { DPPH scavenging activity }(\%)=[1-\text { absorbance of sample/absorbance of blank }] \times 100 \text {. }
$$

Trolox was used as a standard reference and results were expressed as mmol Trolox equivalents (TE) per $100 \mathrm{~g}$ fresh weight (fw).

\section{Total anthocyanin content}

Anthocyanins were extracted from strawberry homogenate $(2 \mathrm{~g})$ with $20 \mathrm{~mL}$ of methanol acidified with $0.1 \% \mathrm{HCl}$ $(\mathrm{v} / \mathrm{v})$. The quantification of total anthocyanins was performed using the $\mathrm{pH}$ differential spectrophotometric method described by Giusti and Wrolstad (2001). Absorbance was measured with a Varian Cary 50 UV spectrophotometer (Varian Co., USA) at 510 and $700 \mathrm{~nm}$ in buffers at $\mathrm{pH} 1.0$ and 4.5. The total anthocyanin content was calculated using the following equation:

Total anthocyanins $(\mathrm{mg} \mathrm{CGE} / \mathrm{L})=(\mathrm{A} \times \mathrm{MW} \times \mathrm{DF} \times 1,000) / \varepsilon$; where $\mathrm{A}=(\mathrm{A} 510-\mathrm{A} 700 \mathrm{~nm}) \mathrm{pH} 1.0-(\mathrm{A} 510-\mathrm{A} 700 \mathrm{~nm})$ $\mathrm{pH}$ 4.5; MW (molecular weight) $=449.2 \mathrm{~g} \cdot \mathrm{mol}^{-1}$ for cyanidin 3-O-glucoside; $\mathrm{DF}=$ dilution factor of the samples; $\varepsilon$ (molar absorptivity of cyanidin-3-glucoside) $=29,600 \mathrm{~L} \cdot \mathrm{mol}^{-1} \cdot \mathrm{cm}^{-1}$ ). Results were expressed as milligrams of cyanidin 3-O-glucoside equivalents (CGE) per $100 \mathrm{~g}$ of fresh weight ( $\mathrm{fw}$ ). 


\section{Statistical analysis}

Results were expressed as means \pm standard deviations. Effect of treatment was analyzed using the least significant difference (LSD) test and differences at $\mathrm{p}<0.05$ were considered to be significant. The statistical analysis was carried out using Statgraphics Centurion XVI software (StatPoint Technologies, VA, USA).

\section{RESULTS AND DISCUSSION}

\section{Weight loss}

The influence of treatments on fruit weight loss is shown in Fig. 1. Weight loss of treated and untreated fruits increased during storage. The loss of weight in all UV-treated fruits was significantly lower than that in control fruit. After 14 days of storage, the loss of weight in control fruits was around 32\% higher compared to UVC treated alone samples. These results are consistent with those of previous studies demonstrating that UVC irradiation stimulated the activity of lignifying enzymes and significantly suppressed the loss of water in fruits (Lu et al. 1991; Bal 2019). Unlike these, Alothman et al. (2009) found no significant difference in the percent weight loss between the UVC treated and the nontreated fresh-cut tropical fruits analyzed, while Maharaj et al. (1999) found that weight loss was higher in UV treated tomato fruits than in the untreated control. Washing with organic acids or AEW caused a significant decrease in moisture loss as compared with water washing. At the end of storage, the highest weight loss was determined in control fruits (1.65\%), while the lowest weight loss was determined in SA + UV (0.37\%) followed by CA + UV-treated fruits $(0.62 \%)$.

(a)

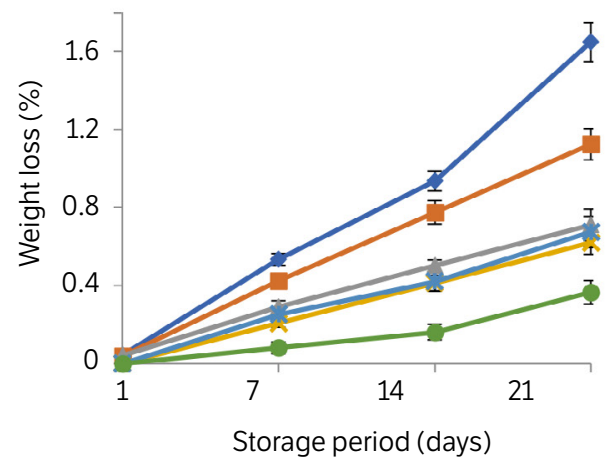

(b)

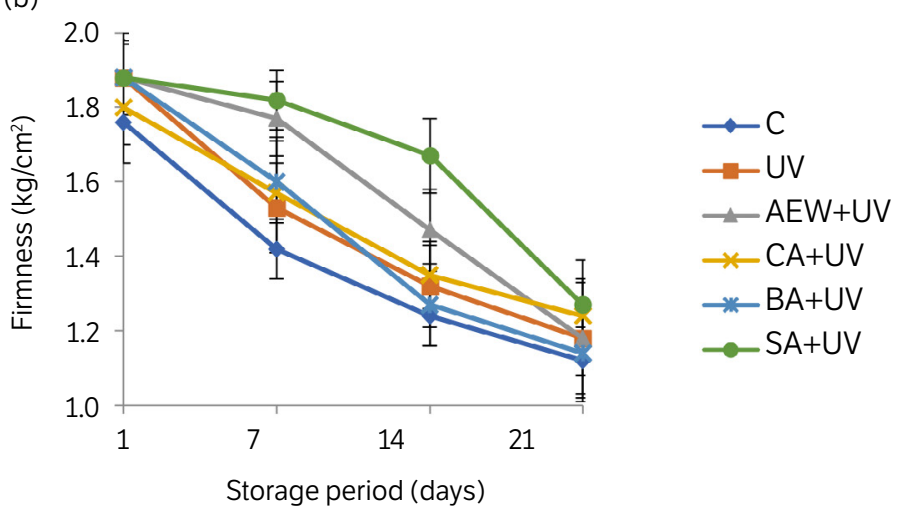

Figure 1. Effect of surface treatments and UVC irradiation on weight loss (a) and firmness (b) of strawberries during storage at $8{ }^{\circ} \mathrm{C}$ for 21 days. (C-control), dipped in tap water; (UV), dipped in tap water and UVC irradiated; (AEW + UV), dipped in acidic electrolyzed water and UVC irradiated; (CA + UV), dipped in $2 \%$ citric acid and UVC irradiated; (BA + UV), dipped in $0.2 \%$ benzoic acid and UVC irradiated; $(S A+U V)$, dipped in $0.2 \%$ sorbic acid and UVC irradiated. Vertical bars represent standard error $(n=3)$.

\section{Firmness}

Firmness is a very important quality factor for postharvest strawberries, as firmer fruits are better able to withstand postharvest handling and transportation (Charles and Arul 2007). The firmness of strawberries decreased during the storage period at $8{ }^{\circ} \mathrm{C}$ in both control and treated fruit. However, UV treatment had a beneficial effect on the fruit firmness, as UV-treated fruits remained significantly firmer than the control throughout the storage period (Fig. 1). 
Similar changes in firmness induced by UVC treatment were reported in strawberries (Baka et al. 1999; Pan et al. 2004; Pombo et al. 2009), peaches (Lu et al. 1991) and mangoes (González-Aguilar et al. 2001). The higher values of firmness found in UVC treated fruit have been attributed to the decreased activity of polygalacturonase and of other cell-wall-degrading enzymes, leading to slowed cell wall degradation, a main factor involved in softening of fleshy fruits (Pan et al. 2004). More recently, Pombo et al. (2009) considered that the effect of UVC irradiation on strawberry fruit softening could be related to the decrease of the transcription of a set of genes involved in cell wall degradation during the first hours after treatment.

The combination of postharvest UV treatment with washing in AEW or organic acids significantly delayed the softening of strawberries stored at $8{ }^{\circ} \mathrm{C}$. No significant differences were found in firmness between UV, CA + UV and $\mathrm{BA}+\mathrm{UV}$-treated samples throughout the storage period. After 14 days of storage, the samples treated with $0.2 \%$ SA followed by UVC (SA + UV) maintained significantly greater firmness than the other treated and control samples. Softening was also significantly delayed in fruit treated with AEW and UVC after 7 days of storage.

\section{Fruit decay}

Fruit decay occurred rapidly in control strawberries stored at $8{ }^{\circ} \mathrm{C}$, with $37.77 \%$ of control fruits showing signs of infection after 14 days of storage (Fig. 2). Treatment with UV alone delayed the appearance of decay in fruits during cold storage. Previously, UV irradiation was found significantly effective in maintaining the quality and delaying the decay and appearance of the fungal growth in strawberries (Baka et al. 1999; Pan et al. 2004; Bal 2019).

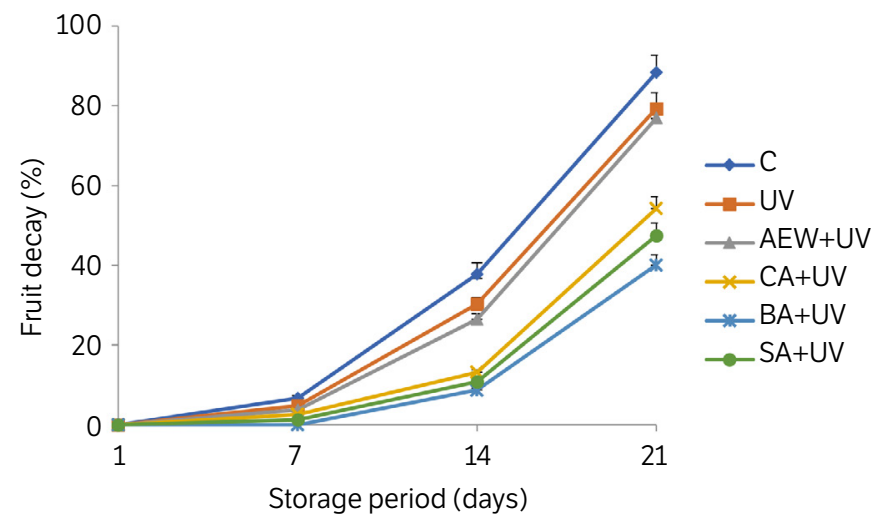

Figure 2. Effect of surface treatments and UVC irradiation on fruit decay in strawberries during storage at $8{ }^{\circ} \mathrm{C}$ for 21 days. (C-control), dipped in tap water; (C+UV), dipped in tap water and UVC irradiated; (AEW + UV), dipped in acidic electrolyzed water and UVC irradiated; (CA + UV), dipped in $2 \%$ citric acid and UVC irradiated; (BA + UV), dipped in $0.2 \%$ benzoic acid and UVC irradiated; (SA + UV), dipped in $0.2 \%$ sorbic acid and UVC irradiated. Vertical bars represent standard error $(n=3)$.

The reduction of fungal decay in strawberries by UV is considered to be due to the germicidal effect of UV light on micro-organisms and to the modification of the fruit physiology through the induction of phytoalexins and possibly other defense mechanisms resulting in a higher disease resistance (Erkan et al. 2008). No significant differences were found in fruit decay between the samples treated with UV alone and the samples washed with AEW before the UV treatment. However, washing with organic acids before the UV treatment significantly reduced the decay of strawberries. In these samples, decay was below $14 \%$ in the 14th day of storage. This could be attributed to the synergistic effect of the treatments on delaying the appearance of mold growth and other physiological processes, like respiration and senescence. At the end of the storage, the highest decay rate was determined in control fruits (83.33\%) and lowest decay rate was determined in BA + UV-treated fruits (40.11\%) followed by SA + UV (47.44\%) and CA + UV (54.26\%) treated fruits. The inhibition of decay could be due to $\mathrm{pH}$ reduction, disturbance of membrane transport and/or permeability, anion accumulation, inhibition of enzymes, cytoplasm acidification, as well as to the specific antimicrobial effect of organic acids (Parish et al. 2003). 


\section{Total soluble solids}

The change in total soluble solids (TSS) content of strawberries as a function of storage time is shown in Fig. 3. Total soluble solids decreased slowly at the beginning of the storage period in all samples. In the last 14 days, it was recorded a notable decrease of TSS in fruits, probably determined by the fruit senescence. No significant difference in TSS content was observed between untreated and treated fruits within the first 14 days of storage. In the last week of the storage period, the combination of washing in organic acids and UV treatment maintained higher levels of TSS in strawberries, as compared to control and UV alone treated samples, by controlling fruit fungal decay and by decreasing the respiration rate and metabolic activity. At the end of 21 days of storage, the highest TSS content was recorded in $\mathrm{BA}+\mathrm{UV}$ and SA + UV treatments (8.8\%), followed by CA + UV treatment (8.5\%), while lowest TSS content was recorded in control (7.9\%) and AEW + UV treatment (7.8\%).

(a)

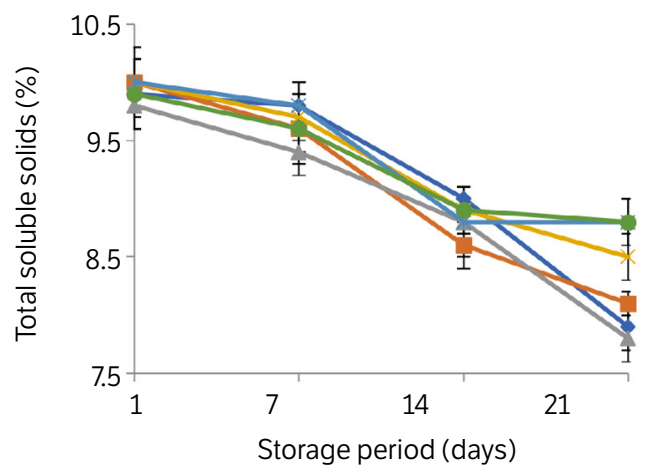

(b)

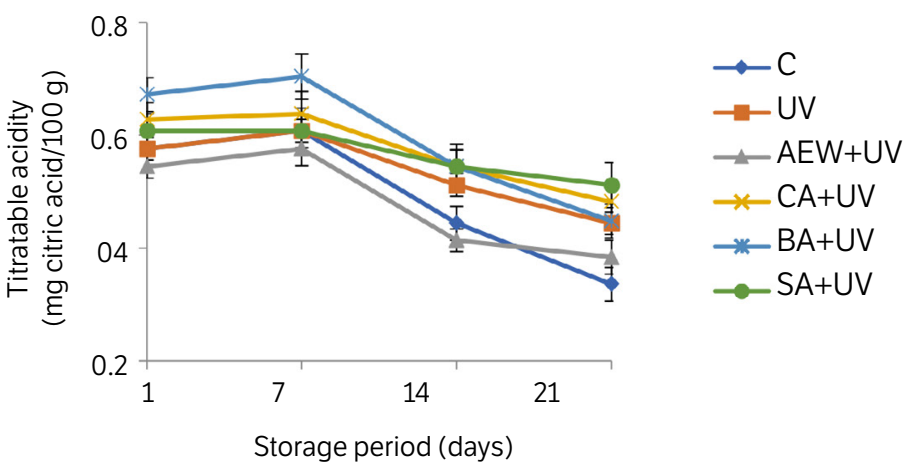

Figure 3. Effect of surface treatments and UVC irradiation on total soluble solids (a) and titratable acidity (b) in strawberries during storage at $8^{\circ} \mathrm{C}$ for 21 days. (C-control), dipped in tap water; (UV), dipped in tap water and UVC irradiated; (AEW + UV), dipped in acidic electrolyzed water and UVC irradiated; (CA + UV), dipped in $2 \%$ citric acid and UVC irradiated; (BA + UV), dipped in $0.2 \%$ benzoic acid and UVC irradiated; $(S A+U V)$, dipped in $0.2 \%$ sorbic acid and UVC irradiated. Vertical bars represent standard error $(n=3)$.

\section{Titratable acidity}

The titratable acidity increased slightly in the first 7 days of storage, but decreased steadily thereafter in all samples (Fig. 3). The decrease of organic acids content during postharvest storage of strawberry fruit has also been reported in previous studies (Koyuncu and Dilmaçünal 2010) and has been attributed to the use of organic acids as respiratory substrates. Titratable acidity decreased at a slower rate in UV treated strawberries as compared with the control, while dipping in organic acids before UV treatment delayed more the acidity decline during storage. Some previous studies also reported that UV treatment decreased the respiration rate and maintained a higher acidity in strawberries (Baka et al. 1999) and peaches (Lu et al. 1991).

\section{Total anthocyanin content}

Total anthocyanins content in control strawberries was $53.08 \mathrm{mg}$ CGE·100 $\mathrm{g}^{-1}$. The anthocyanin content gradually increased during storage up to the 14th day in UV-treated fruits dipped in organic acids, while a slight decrease has been recorded in control fruits and AEW + UV-treated fruits (Fig. 4). Further, the anthocyanin content recorded a sharp decline in all samples until the 21 st day of storage, when fruits could be considered as over-ripe and in senescence. Other previous studies also reported a similar pattern of initial increase in anthocyanins followed by decrease after prolonged storage of 
strawberry fruit (Zheng et al. 2007; Bal 2019). Fruits treated with UV tended to have higher total anthocyanin content as compared to control fruits after the first 14 days of storage. Ultraviolet treatment has also been shown to affect changes in anthocyanin content in strawberries in other studies (Erkan et al. 2008; Bal 2019).

(a)

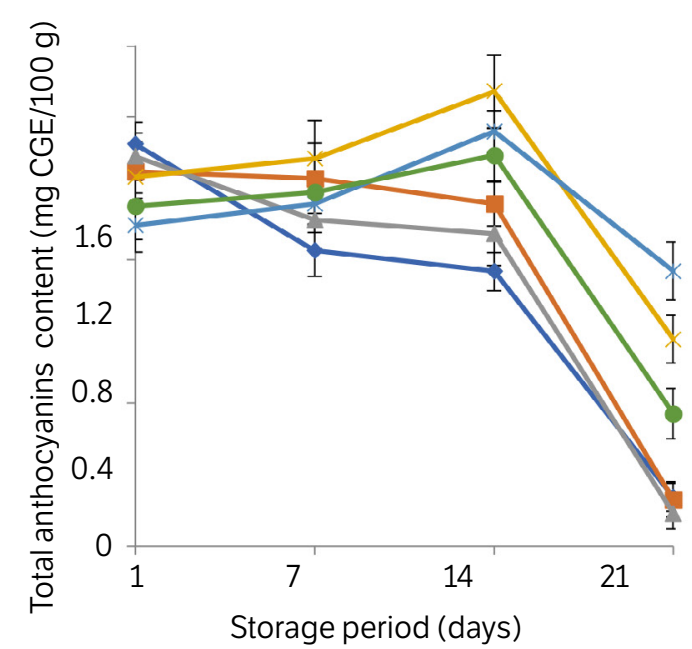

(c)

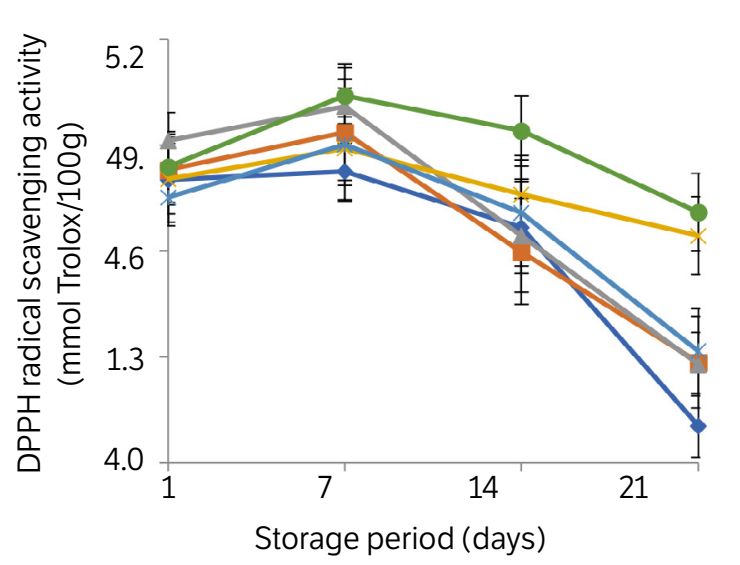

(b)

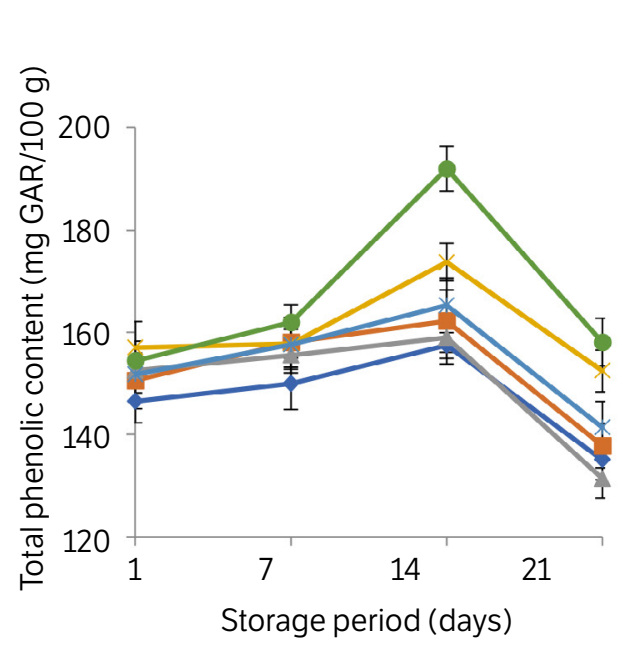

$\leftrightarrow C$

$\rightarrow-U V$

$\leadsto A E W+U V$

$\because \mathrm{CA}+\mathrm{UV}$

$\because B A+U V$

$\rightarrow$ SA+UV

Figure 4. Effect of surface treatments and UVC irradiation on total anthocyanins content (a), total phenolic content (b) and DPPH radical scavenging activity (c) in strawberries during storage at $8^{\circ} \mathrm{C}$ for 21 days. (C-control), dipped in tap water; (C+UV), dipped in tap water and UVC irradiated; $(A E W+U V)$, dipped in acidic electrolyzed water and UVC irradiated; (CA + UV), dipped in $2 \%$ citric acid and UVC irradiated; (BA + UV), dipped in $0.2 \%$ benzoic acid and UVC irradiated; (SA $+U V$ ), dipped in $0.2 \%$ sorbic acid and UVC irradiated. Vertical bars represent standard error $(n=3)$.

\section{Total phenolic content}

In this study, the mean total phenolic content of strawberries was $144.55 \mathrm{mg} \mathrm{GAE} \cdot 100 \mathrm{~g}^{-1}$ on the treatment day. Immediately after treatments, no significant difference in the total phenolic content was found. The total phenolic contents of strawberry fruit increased in all UV treated and control samples during 14 days storage period, thereafter they decreased sharply during the remainder of storage (Fig. 4). However, the increase was relatively lower in control fruit as compared to UV treated fruit. The surface treatment with organic acids before UV irradiation showed a positive effect in maintaining higher concentration of total phenolics. The highest phenolic content was found with SA + UV (191.96 mg GAE $\left.100 \mathrm{~g}^{-1}\right)$ followed by CA + UV treatment (173.72 mg GAE·100 $\left.\mathrm{g}^{-1}\right)$ and the lowest one was found in control (157.45.4 mg GAE·100 g $\left.\mathrm{g}^{-1}\right)$ after 14 days of storage. 
These results are consistent with previous studies demonstrating that UV irradiation induces the accumulation of phenolic compounds in fruits (González-Aguilar et al. 2001; Erkan et al. 2008). This effect has been attributed to the activation of phenylalanine ammonia-lyase, which is one of the key enzymes in the synthesis of phenolic compounds in plant tissues, and to the enhancement of phenolic extractability as a result of the depolymerization and dissolution of the cell wall polysaccharides (Alothman et al. 2009). The decrease in total phenolic content observed after 14 days of storage might be attributed, at least in parts, to the degradation of anthocyanins.

\section{Antioxidant activity}

Initially, the mean DPPH antioxidant activity of strawberries was $4.8 \mathrm{mmol}$ Trolox $100 \mathrm{~g}^{-1} \mathrm{fw}$. The DPPH values of strawberries slightly increased in all samples during the first 7 days storage at $8{ }^{\circ} \mathrm{C}$ and decreased thereafter until the end of the storage period (Fig. 4). However, this increase was relatively lower in control fruit when compared to all UV treated fruits. After 14 days of storage, SA + UV strawberry fruits had the highest DPPH values, followed by CA + UV-treated samples. Moreover, these treatments recorded the smallest decreases in antioxidant activity in the last two weeks of storage. At the end of storage, control fruits had the lowest DPPH value, which was only $4.11 \mathrm{mmol}$ Trolox $100 \mathrm{~g}^{-1}$. Results are in good agreement with previous studies, showing that UVC treatment increased the antioxidant activity of fruits (GonzálezAguilar et al. 2001; Erkan et al. 2008).

\section{CONCLUSION}

Results showed that $2 \mathrm{~kJ} \cdot \mathrm{m}^{-2} \mathrm{UV}$ irradiation of fresh strawberries significantly suppressed the loss of water, maintained firmness and delayed the appearance of decay symptoms in fruits during cold storage. In addition, UV treatment alone promoted the accumulation of phenolics and increased the antioxidant activity of strawberries.

Use of chemical dips before the UV treatment significantly reduced the postharvest decay of strawberries $(0.2 \% \mathrm{BA}>0.2 \% \mathrm{SA}>2 \% \mathrm{CA})$ and was more effective in maintaining the content of health promoting compounds (polyphenols, anthocyanins) and antioxidant capacity of the fruits as against the UV treatment alone. The results suggest that postharvest treatments of strawberries with organic acids followed by UV irradiation may be a useful way of maintaining strawberry fruit quality and extending their postharvest life.

\section{AUTHORS' CONTRIBUTION}

Conceptualization: Nour V.; Methodology: Nour V. and Ionica M. E.; Investigation: Nour V., Plesoianu A. M. and Ionica M. E.; Writing - Original Draft: Nour V.; Writing - Review and Editing: Nour V. and Plesoianu A. M.; Resources: Nour V. and Ionica M. E.; Supervision: Nour V.

\section{DATA AVAILABILITY STATEMENT}

All dataset were generated or analyzed in the current study.

\section{FUNDING}

Not applicable. 


\section{ACKNOWLEDGMENTS}

This work benefited from the networking activities within the European funded COST ACTION CA18113 - Understanding and exploiting the impacts of low $\mathrm{pH}$ on micro-organisms.

\section{REFERENCES}

Aday, M. S., Buyukcan, M. B. and Caner, C. (2013). Maintaining the quality of strawberries by combined effect of aqueous chlorine dioxide with modified atmosphere packaging. Journal of Food Processing and Preservation, 37,568-581. https://doi.org/10.1111/.1745-4549.2012.00697.x

Alothman, M., Bhat, R. and Karim, A. A. (2009). UV radiation-induced changes of antioxidant capacity of fresh-cut tropical fruits. Innovative Food Science and Emerging Technologies, 10, 512-516. https://doi.org/10.1016/j.ifset.2009.03.004

Baka, M., Mercier, J., Corcuff, R., Castaigne, F. and Arul, J. (1999). Photochemical treatment to improve storability of fresh strawberries. Journal of Food Science, 64, 1068-1072. https://doi.org/10.1111/j.1365-2621.1999.tb12284.x

Bal, E. (2019). Influence of chitosan-based coatings with UV irradiation on quality of strawberry fruit during cold storage. Turkish Journal of Agriculture - Food Science and Technology, 7, 275-281. https://doi.org/10.24925/turjaf.v7i2.275-281.2252

Bianco, L., Lopez, L., Scalone, A. G., Di Carli, M., Desiderio, A., Benvenuto, E., Perrotta, G. (2009). Strawberry proteome characterization and its regulation during fruit ripening and in different genotypes. Journal of Proteomics, 72, 586-607. https://doi.org/10.1016/j.jprot.2008.11.019

Charles, M. T. and Arul, J. (2007). UV treatment of fresh fruits and vegetables for improved quality: a status report. Stewart Postharvest Review, 3, 1-8. https://doi.org/10.2212/spr.2007.3.6

Collins, J. K. and Perkins-Veazie, P. (1993). Postharvest Changes in Strawberry Fruits Stored Under Simulated Retail Display Conditions. Journal of Food Quality, 16, 133-143. https://doi.org/10.1111/j.1745-4557.1993.tb00356.x

Deng, L.-Z., Mujumdar, A. S., Pan, Z., Vidyarthi, S. K., Xu, J., Zielinska, M. and Xiao, H.-W. (2020). Emerging chemical and physical disinfection technologies of fruits and vegetables: a comprehensive review. Critical Reviews in Food Science and Nutrition, 60, 24812508. https://doi.org/10.1080/10408398.2019.1649633

Erkan, M., Wang, S. Y. and Wang, C. Y. (2008). Effect of UV treatment on antioxidant capacity, antioxidant enzyme activity and decay in strawberry fruit. Postharvest Biology and Technology, 48, 163-171. https://doi.org/10.1016/j.postharvbio.2007.09.028

Giusti, M. M. and Wrolstad, R. E. (2001). Unit F1.2. Anthocyanins. Characterization and measurement with UV-visible spectroscopy. In R. E. Wrolstad and S. J. Schwartz (Eds.), Current protocols in food analytical chemistry (p. 1-13). Hoboken: John Wiley \& Sons. https:// doi.org/10.1002/0471142913.faf0102s00

González-Aguilar, G. A., Wang C. Y., Buta G. J. and Krizek D. T. (2001). Use of UV-C irradiation to prevent decay and maintain postharvest quality of ripe 'Tommy Atkins' mangoes. International Journal of Food Science and Technology, 36, 767-773. https://doi. org/10.1111/j.1365-2621.2001.00522.x

Graça, A., Abadias, M., Salazar, M. and Nunes, C. (2011). The use of electrolyzed water as a disinfectant for minimally processed apples. Postharvest Biology and Technology, 61, 172-177. https://doi.org/10.1016/j.postharvbio.2011.04.001

Guo, M., Jin, T. Z., Gurtler, J. B., Fan, X. and Yadav, M. P. (2018). Inactivation of Escherichia coli O157:H7 and Salmonella and native microbiota on fresh strawberries by antimicrobial washing and coating. Journal of Food Protection, 81, 1227-1235. https://doi.org/10.4315/0362028X.JFP-18-007 
Issa-Zacharia, A., Kamitani, Y., Miwa, N., Muhimbula, H. and Iwasaki, K. (2011). Application of slightly acidic electrolyzed water as a potential non-thermal food sanitizer for decontamination of fresh ready-to-eat vegetables and sprouts. Food Control, 22, 601-607. https:// doi.org/10.1016/j.foodcont.2010.10.011

Jin, P., Wang, H., Zhang, Y., Huang, Y., Wang, L. and Zheng, Y. (2017). UV-C enhances resistance against gray mold decay caused by Botrytis cinerea in strawberry fruit. Scientia Horticulturae, 225, 106-111. https://doi.org/10.1016/j.scienta.2017.06.062

Koide, S., Shitanda, D., Note, M. and Cao, W. (2011). Effects of mildly heated, slightly acidic electrolyzed water on the disinfection and physicochemical properties of sliced carrot. Food Control, 22, 452-456. https://doi.org/10.1016/j.foodcont.2010.09.025

Koyuncu, M. A. and Dilmaçünal, T. (2010). Determination of Vitamin C and Organic Acid Changes in Strawberry by HPLC During Cold Storage. Notulae Botanicae Horti Agrobotanici Cluj-Napoca 38, 95-98.

Lin, M. G., Lasekan, O., Saari, N., Khairunniza-Bejo, S. (2017). The effect of the application of edible coatings on or before ultraviolet treatment on postharvested Longan fruits. Hindawi Journal of Food Quality, 2017, 5454263. https://doi.org/10.1155/2017/5454263

Lu, J. Y., Stevens, C., Khan, V. A., Kabwe, M. and Wilson, C. L. (1991). The effect of ultraviolet irradiation on shelf-life and ripening of peaches and apples. Journal of Food Quality. 14, 299-305. https://doi.org/10.1111/j.1745-4557.1991.tb00070.x

Ma, L., Zhang, M., Bhandari, B. and Gao, Z. (2017). Recent developments in novel shelf life extension technologies of fresh-cut fruits and vegetables. Trends in Food Science \& Technology, 64, 23-38. https://doi.org/10.1016/j.tifs.2017.03.005

Maharaj, R., Arul, J. and Nadeau, P. (1999). Effect of photochemical treatment in the preservation of fresh tomato (Lycopersicon esculentum, cv. Capello) by delaying senescence. Postharvest Biology and Technology, 15, 13-23. https://doi.org/10.1016/S0925-5214(98)00064-7

Moya-León, M. A., Mattus-Araya, E. and Herrera, R. (2019). Molecular events occurring during softening of strawberry fruit. Frontiers in Plant Sciences, 10, 615. https://doi.org/10.3389/fpls.2019.00615

Nicolau-Lapeña, I., Abadias, M., Bobo, G., Aguiló-Aguayo, I., Lafarga, T. and Viñas, I. (2019). Strawberry sanitization by peracetic acid washing and its effect on fruit quality. Food Microbiology, 83, 159-166. https://doi.org/10.1016/j.fm.2019.05.004

Oliveira, I., Sousa, A., Ferreira, I. C. F. R., Bento, A., Estevinho, L. and Pereira, J. A. (2008). Total phenols, antioxidant potential and antimicrobial activity of walnut (Juglans regia L.) green husks. Food and Chemical Toxicology, 46, 2326-2331. https://doi.org/10.1016/j.fct.2008.03.017

Pablos, C., Romero, A., Diego, A., Vargas, C., Bascón, I., Pérez-Rodríguez, F. and Marugán, J. (2018). Novel antimicrobial agents as alternative to chlorine with potential applications in the fruit and vegetable processing industry. International Journal of Food Microbiology, 285, 92-97. https://doi.org/10.1016/j.jijfoodmicro.2018.07.029

Pan, J., Vicente, A. R., Martínez, G. A., Chaves, A. R. and Civello, P. M. (2004). Combined use of UV C irradiation and heat treatment to improve postharvest life of strawberry fruit. Journal of the Science of Food and Agriculture, 84, 1831-1838. https://doi.org/10.1002/jsfa.1894

Parish, M. E., Beuchat, L. R., Suslow, T. V., Harris, L. J., Garrett, E. H., Farber, J. N. and Busta, F. F. (2003). Methods to Reduce/Eliminate Pathogens from Fresh and Fresh Cut Produce. Comprehensive Reviews in Food Science and Food Safety, 2, 161-173. https://doi. org/10.1111/j.1541-4337.2003.tb00033.x

Parvez, S. and Wani, I. A. (2018). Postharvest Biology and Technology of Strawberry. In S. Mir, M. Shah and M. Mir (Eds.), Postharvest Biology and Technology of Temperate Fruits (p. 331-348). Cham: Springer. https://doi.org/10.1007/978-3-319-76843-4_14

Pombo, M. A., Dotto, M. C., Martínez, G. A. and Civello, P. M. (2009). UV-C irradiation delays strawberry fruit softening and modifies the expression of genes involved in cell wall degradation. Postharvest Biology and Technology, 51, 141-148. https://doi.org/10.1016/j. postharvbio.2008.07.007

Severo, J., Oliveira, I. R., Tiecher, A., Chaves, F. C. and Rombaldi, C. V. (2015). Postharvest UV-C treatment increases bioactive, ester volatile compounds and a putative allergenic protein in strawberry. LWT-Food Science and Technology, 64, 685-692. https://doi.org/10.1016/j. Iwt.2015.06.041 
Singleton, V. L. and Rossi, J. A. (1965). Colorimetry of Total Phenolics with Phosphomolybdic-Phosphotungstic Acid Reagents. American Journal of Enology and Viticulture, 16, 144-158.

Wang, H., Jiang, L., Wang, H., Yu, X., Jin, P. and Zheng, Y. (2015). Effects of UV-C Treatment on Postharvest Decay, Antioxidant Activity and Phenylpropanoid Metabolism in Strawberry Fruit. Food Science,10.

Zheng, Y., Wang, S. Y., Wang, C. Y. and Zheng, W. (2007). Changes in strawberry phenolics, anthocyanins and antioxidant capacity in response to high oxygen treatments. LWT-Food Science and Technology, 40, 49-57. https://doi.org/10.1016/j.Iwt.2005.08.013 